\title{
Virgin olive oil blended polyurethane micro/nanofibers ornamented with copper oxide nanocrystals for biomedical applications
}

This article was published in the following Dove Press journal:

International Journal of Nanomedicine

13 February 2014

Number of times this article has been viewed

\author{
Touseef Amna' \\ M Shamshi Hassan ${ }^{2}$ \\ jieun Yang' \\ Myung-Seob Khil ${ }^{2}$ \\ Ki-Duk Song ${ }^{3}$ \\ Jae-Don $\mathrm{Oh}^{3}$ \\ Inho Hwang' \\ 'Department of Animal Sciences \\ and Biotechnology, ${ }^{2}$ Department \\ of Organic Materials and Fiber \\ Engineering, Chonbuk National \\ University, Jeonju, South Korea; \\ ${ }^{3}$ Genomic Informatics Center, \\ Hankyong National University, \\ Anseong, South Korea
}

\begin{abstract}
Recently, substantial interest has been generated in using electrospun biomimetic nanofibers of hybrids, particularly organic/inorganic, to engineer different tissues. The present work, for the first time, introduced a unique natural and synthetic hybrid micronanofiber wound dressing, composed of virgin olive oil/copper oxide nanocrystals and polyurethane (PU), developed via facile electrospinning. The as-spun organic/inorganic hybrid micronanofibers were characterized by scanning electron microscopy (SEM), energy dispersive X-ray analysis, X-ray diffraction, electron probe microanalysis, and transmission electron microscopy. The interaction of cells with scaffold was studied by culturing NIH 3 T3 fibroblasts on an as-spun hybrid micronanofibrous mat, and viability, proliferation, and growth were assessed. The 3-(4,5-dimethylthiazol-2-yl)2,5-diphenyltetrazolium bromide assay results and SEM observation showed that the hybrid micronanofibrous scaffold was noncytotoxic to fibroblast cell culture and was found to benefit cell attachment and proliferation. Hence our results suggest the potential utilization of as-spun micronanoscaffolds for tissue engineering. Copper oxide-olive oil/PU wound dressing may exert its positive beneficial effects at every stage during wound-healing progression, and these micronanofibers may serve diverse biomedical applications, such as tissue regeneration, damaged skin treatment, wound healing applications, etc. Conclusively, the fabricated olive oil-copper oxide/ PU micronanofibers combine the benefits of virgin olive oil and copper oxide, and therefore hold great promise for biomedical applications in the near future.
\end{abstract}

Keywords: micronanofibers, copper oxide, wound healing, polyurethane, olive oil

\section{Introduction}

Recently the fabrication of nanofibers by electrospinning technique has attracted enormous interest as a method to craft tissue engineering applications. By using the electrospinng procedure, fibers with modifiable dimensions can be produced, and the diameter of these electrospun fibers may be comparable to fibrils in the extracellular matrix (ECM). ${ }^{1}$ Such electrospun fibers have huge potential as a substrate for cell growth. Additionally, nanofibers have demonstrated effectiveness as wound dressings aiding in wound healing. ${ }^{2-4}$ Wound dressings play a significant role in varied wounds or injuries, such as traumatic wounds, chronic wounds, and burns. Dressing materials have been shown to afford advantages in the would healing process, such as enhancing epithelialization as well as preventing wound infection. ${ }^{5,6}$ Skin is the outer covering of vertebrates, and in mammals including humans, it is the largest organ, the integumentary system, which forms the protective layer that guards against various types of injuries.

\footnotetext{
Correspondence: Inho Hwang: Touseef Amna

Department of Animal Sciences and Biotechnology, Chonbuk National University Jeonju, Jeollabuk-do 56I-756, South Korea

$\mathrm{Tel}+8263270235$ I

Fax +82632704249

Email inho.hwang@jbnu.ac.kr; touseefamna@gmail.com
} 
An injury or wound occurs due to multiple reasons, such as trauma or burn, and the remedial procedure is expensive. Globally, 10 million people are suffering from burns and chronic wounds which require medical attention. In this regard, a wound dressing material that possesses the desired characteristics can help to relieve pain and reduce risk of infection. ${ }^{7}$ Ideally, wound dressings should act as a barrier against microbes and should prevent the growth of microorganisms on the wound surface. ${ }^{8}$ As well, the designed scaffold should be able to imitate the morphological features and biological functionality of natural ECM proteins. Moreover, the model wound bandage should be capable of absorbing wound exudates and should be biodegradable. ${ }^{9}$ Considering all these factors, it is essential to develop a new wound dressing material which possesses all of these essential requirements. We aimed to design a durable organic/inorganic hybrid wound dressing and to investigate its potential for wound management and healing.

Earlier studies have reported wound dressing applications of chitin and chitosan. ${ }^{10}$ For instance, carboxyethyl chitosan/ poly(vinyl alcohol)/silk fibroin-based wound dressings have been proposed for skin regeneration. ${ }^{11}$ In another report, sodium alginate/poly(vinyl alcohol)/nano zinc oxide composite nanofibers for antibacterial wound dressings have been designed. ${ }^{12}$ Nevertheless, to our knowledge, there is no report on the fabrication of copper oxide $(\mathrm{CuO})$ and virgin olive oil-based wound dressings. To this end, we herein report the synergistic outcome of $\mathrm{CuO}$ and virgin olive oil for enhanced wound-healing application.

The medicinal benefits of olive oil are undoubtedly huge and have been extensively reported in the literature. ${ }^{13-18}$ Ultraviolet (UV) rays exert a negative effect on all antioxidants, especially on carotenoids. Therefore, an adequate intake of carotenoids in the form of vegetable and extra virgin olive oil (which contains $\beta$-carotene and lutein) has been recommended to obtain these important protective skin factors. Besides photoprotection for $\operatorname{skin}^{19,20}$ olive oil has direct antioxidant action on skin, mainly through oleuropein, ${ }^{21}$ which acts as a free radical scavenger. Furthermore, in order to impart or enhance the antimicrobial activity of wound dressing, it is necessary to incorporate into it efficient antibacterial agents. It is well known that silver, copper, and zinc are chemically stable and possess excellent antimicrobial activity with little toxic reaction. Besides possessing broad antimicrobial activity, copper also plays a significant role in various physiological and metabolic processes such as stimulation of endothelial growth, angiogenesis, and stabilization of extracellular skin proteins. ${ }^{22}$ In contrast, the unpleasant skin response to copper is negligible. ${ }^{23}$ Conclusively, considering the potential of nanofibrous polyurethane (PU) membrane to enhance epithelial growth ${ }^{5}$ and the aforementioned applications of olive oil and copper, an organic/ inorganic hybrid micronanofibrous dressing was fabricated via facile electrospinning. We believe these biodegradable micronanofibers aid in quick healing as well as decrease the risk of wound infection.

\section{Materials and methods \\ Chemicals and cells}

Olive oil (Spain extra virgin olive 100\%) was procured from the local market (Jeonju, South Korea). The 3-(4,5-dimethylthiazol-2-yl)-2,5-diphenyltetrazolium bromide (MTT) reagent, dimethyl sulfoxide, and copper (II) acetate precursor were obtained from Sigma-Aldrich (St Louis, MO, USA). PU (molecular weight $=110,000$ ) was purchased from CardioTech International, Inc. (Wilmington, MA, USA), and tetrahydrofuran and $N, N$-dimethylformamide were from Showa Chemical Industry Ltd (Tokyo, Japan). NIH 3T3 mouse fibroblasts were purchased from American Type Culture Collection (Manassas, VA, USA). Penicillin/streptomycin solution and Dulbecco's Modified Eagle's Medium (DMEM) were from Life Technologies (Carlsbad, CA, USA). Laboratory ware was purchased from BD, Franklin Lakes, NJ, USA.

\section{Preparation of $\mathrm{CuO}$ quantum dots}

The preparation of $\mathrm{CuO}$ quantum dots was carried out by the wet chemical method described in our previous work. ${ }^{24}$ In brief $0.1 \mathrm{M} \mathrm{Cu}\left(\mathrm{CH}_{3} \mathrm{COO}\right)_{2}$, solution was mixed with 0.5 $\mathrm{M}$ hexamethylenetetramine solution with continuous stirring at $100^{\circ} \mathrm{C}$ until the precipitate was formed. The precipitate was filtered and dried in an $80^{\circ} \mathrm{C}$ oven. The resulting copper nanocrystals were fully characterized and used for the fabrication of micronanofibers.

\section{Preparation of hybrid wound dressing by electrospinning}

Preparation of pure and hybrid micronanofibrous mats was carried out by electrospinning as described elsewhere. ${ }^{24} \mathrm{PU}$ polymeric beads (10 $\left.\mathrm{wt} \%\right)$ were dissolved in $N, N$-dimethylformamide: tetrahydrofuran $(1: 1 \mathrm{w} / \mathrm{w})$ by magnetic stirring overnight at room temperature to yield a clear solution. The PU/olive oil blends were obtained by adding different weight $\%$ ( $5 \%$ and $10 \%$ ) of oil. The respective blends were mixed at room temperature to obtain uniform olive oil/ PU mixtures. The final composite mixture was prepared by 
mixing $5 \mathrm{wt} \%$ of virgin olive oil and $3 \mathrm{wt} \%$ of $\mathrm{CuO}$ nanocrystals in a $10 \mathrm{wt} \% \mathrm{PU}$ polymeric solution. The composite mixture was stirred for 1 hour prior to electrospinning. The obtained pristine and composite sol-gels were transferred to a plastic syringe with micropipette tip $(200 \mu \mathrm{L})$ at head (Shinchang Medical Co, Ltd, Gyeongsangbuk-do, South Korea). The microtip (internal diameter $=0.6 \mathrm{~mm}$ ) was used as the spinning head. A voltage of $15 \mathrm{kV}$ was applied to this solution, and the distance between the syringe needle tip and collector was maintained at $10 \mathrm{~cm}$ during electrospinning. A copper pin inserted in the solution was used as a positive terminal, whereas a ground iron drum covered by a polyethylene sheet was used as the counter electrode. The micronanofibers collected on the polyethylene sheet were dried in an oven to remove the leftover solvent.

\section{Physicochemical categorization}

The morphology and elemental composition of undoped $\mathrm{PU}$, oil blended PU, and olive oil/CuO/PU hybrid mats were analyzed by scanning electron microscopy (SEM) (S-7400; Hitachi Ltd, Tokyo, Japan), coupled with energy dispersive $\mathrm{X}$-ray spectrometer (EDX). The SEM images were captured at high and low magnifications, and the distribution of elements was measured using electron probe microanalysis. Crystalline structure study of pure and hybrid micronanofibers was carried out by X-ray diffraction (XRD) on a D/MAX 2500 diffractometer (Rigaku Corporation, Tokyo, Japan) with copper $\mathrm{K} \alpha$ radiation $(\lambda=1.540 \AA)$ over Bragg angles ranging between $10^{\circ}-80^{\circ}$, at a $30 \mathrm{kV}$ operating voltage and $40 \mathrm{~mA}$ current.

\section{Culture preparation}

Cell seed preparation and viability testing were performed as described by Hassan et al. ${ }^{25}$ DMEM medium (containing $10 \%$ fetal calf serum and $1 \%$ penicillin/streptomycin solution) was used for cell culture, and cultured cells were maintained at $37^{\circ} \mathrm{C}$ in $5 \%$ carbon dioxide and $95 \%$ air. To avoid contamination, UV irradiation was used for the sterilization of pristine and hybrid micronanofibers. For cell seeding, the synthesized scaffolds were typically soaked in the growth medium for a few hours to aid in the appropriate attachment of cells to nanomatrix. Subsequently, fibroblasts were seeded to $60 \%$ confluency (cell count $=1 \times 10^{5}$ cells $/ \mathrm{mL}$ ) in 96-well microplates and allowed to grow for 3 days. The growth medium was changed at regular time intervals. Cells cultured without the micronanofibers served as a control.

Cell viability was measured by MTT assay. MTT reagent was prepared by strictly following the manufacturer's instructions and was stored in the dark at $4^{\circ} \mathrm{C}$ until use. Briefly, following the incubation of cells with pristine and hybrid wound dressings for 1,2 , and 3 days, $40 \mu \mathrm{L}$ of MTT reagent was added to each well which contained $160 \mu \mathrm{L}$ growth medium and was incubated for 4 hours at $37^{\circ} \mathrm{C}$. Absorbance was detected at $490 \mathrm{~nm}$ using an enzyme-linked immunosorbent assay plate reader (BioTek Instruments Inc, Winooski, VT, USA).

\section{Cell attachment study}

To check the interaction between the cells and the nanomatrix, cells were cultured on the as-spun micronanofibers. Cell fixation was carried out at the end of the incubation period. Briefly, cultured cells were washed with phosphate buffered saline (PBS) to remove the remaining medium and nonadherent cells. Cells were fixed with glutaraldehyde $(2.5 \% \mathrm{v} / \mathrm{v})$ and were incubated for approximately 1-2 hours. After incubation, the fixed cells were washed again and dehydrated with increasing concentrations of ethanol (20\%-100\%). The samples were then dried, and the cell attachment and spreading behavior were monitored by SEM as described.

\section{$\mathrm{CuO}$ migration from the micronanofibrous mat}

The fabricated composite micronanofibrous scaffold was analyzed for the $\mathrm{CuO}$ migration. We tested $\mathrm{CuO}$ migration by following the method of Sheikh et al with suitable modifications. ${ }^{26}$ Briefly, a known weight $(10 \mathrm{mg})$ of the composite mat was incubated in $\mathrm{PBS}(\mathrm{pH} 7.4)$ at $37^{\circ} \mathrm{C}$ with constant agitation on a rotary incubator shaker for 1 week. PBS was replaced every 12 hours with fresh PBS for up to 1 week. After 1 week of incubation, the micronanofibrous mat was vacuum dried and UV-diffuse reflectance spectroscopic (UV-DRS) measurements of the mats were taken before and after incubation in PBS. UV-DRS was performed at the wavelength range of 200-900 $\mathrm{mm}$. Moreover, the color of incubated mat and incubation medium (PBS) was also monitored regularly.

\section{Results}

Figure 1 represents the digital images of pristine and composite micronanofibrous mats. The color of the mat has been changed from white to mustard color, which is preliminary evidence of integration of olive oil and $\mathrm{CuO}$ nanocrystals with PU. Figure 2 shows the SEM micrographs of the plain $\mathrm{PU}$, virgin olive oil blended PU, and olive oil/CuO-PU hybrid micronanofibers. Electrospinning of pristine PU solutions yielded nanofibers with $250-550 \mathrm{~nm}( \pm 10 \mathrm{~nm})$ diameter 


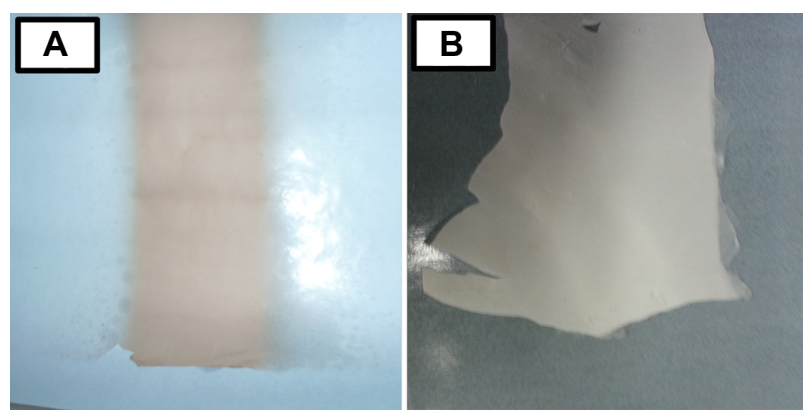

Figure I Digital images of the electrospun pristine PU mat $(\mathbf{A})$ and the hybrid micronanofibrous mat (B).

Abbreviation: $\mathrm{PU}$, polyurethane.

demonstrated in Figure 2A. Undoped PU nanofibers were bead-free, with even surfaces (Figure 2B). Conversely, the nanofibers obtained from olive oil doping (5\%) in PU were comparatively beaded (Figure 2B). Furthermore, it was also observed that the merging of olive oil and $\mathrm{CuO}$ nanocrystals in PU yielded micronanofibers which ranged from $0.15-1.5 \mu \mathrm{m}$ in diameter, with fused morphology (at certain positions) and enhanced mechanical strength (Figure $2 \mathrm{C}$ and D). The optimal concentration of olive oil for spinning was found to be approximately $5 \%$, and the interaction of olive oil with PU resulted in hybrid fiber morphology (micronanofibers) (Figure 2B-D), which further confirmed the even distribution of oil and $\mathrm{CuO}$ in PU. Figure 3 represents the chemical composition of hybrid micronanofibers. The successful blending of $\mathrm{CuO}$ nanocrystals and olive oil with PU fibers was confirmed by electron probe microanalysis, which demonstrated consistent dispersion of carbon, oxygen, and copper elements in hybrid mat. Figure 4A shows transmission electron microscopy

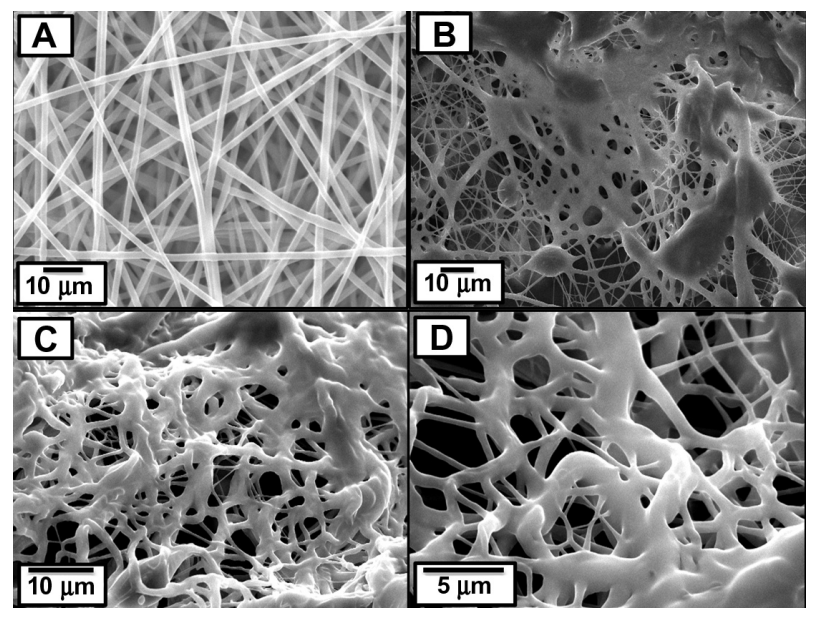

Figure 2 SEM images of pristine PU (A), olive oil (10 wt\%)/PU blend micronanofibers (B), and olive oil (5 wt\%)/CuO-PU micronanofibers at different magnifications ( $\mathbf{C}$ and $\mathbf{D})$.

Abbreviations: $\mathrm{CuO}$, copper oxide; PU, polyurethane; SEM, scanning electron microscopy.
(TEM) of the hybrid mat. The TEM image demonstrates that the hybrid fibers contain beaded morphology due to the presence of olive oil and $\mathrm{CuO}$ nanocrystals. The particle size of $\mathrm{CuO}$ nanocrystals was $\sim 6.0 \pm 0.5 \mathrm{~nm}$ (inset Figure $4 \mathrm{~A}$ ), and these tiny $\mathrm{CuO}$ nanocrystals were supposed to be present inside the fibers making the core shell structure. Figure 4B shows the EDX analysis of hybrid micronanofibers. As revealed by the figure, the fibers composed of carbon, oxygen, and copper are without impurities. Also, the line mapping of the fibers shows the signals of these elements, which again confirms their presence in the composite (inset Figure 4B).

Figure 5 depicts the XRD of hybrid micronanofibers. A low intensity, broad peak at $\sim 20$ degrees (Figure $5 \mathrm{~A}$ ) was observed in undoped PU nanofibers, which is due to the amorphous nature of the polymer. A similar but intense peak was observed at $\sim 20$ degrees in the case of oil doped PU micronanofibers (Figure 5B). The alteration in the intensity of the peak is attributed to the interaction of olive oil. Figure $5 \mathrm{C}$ depicts the XRD of hybrid mat; the peaks at $35.5^{\circ}$ and $38.7^{\circ}$ represent Bragg's reflection from (111) and (111) planes of $\mathrm{CuO}$ (Joint Committee on Powder Diffraction Standards number 05-661), which verified the homogeneous incorporation of $\mathrm{CuO}$ nanoparticles in the hybrid micronanofibrous mats. Therefore, fabrication of olive oil/PU-CuO micronanofibers was again confirmed by EDX and XRD spectra.

The cytobiocompatibility of as-spun organic/inorganic hybrid micronanofibers was investigated using fibroblasts. Figure 6A shows the MTT assay results after specific incubation times. No toxic effects were seen in the fibroblasts cultured on hybrid micronanofibers and untreated control. Cell numbers increased exponentially during the culture period, and were active throughout the incubation time. The morphology and spreading behavior of fibroblasts on the hybrid miconanofibers were analyzed by SEM at the end of incubation, and results (Figure 6B) confirm that the cells maintained their morphology and growth pattern. Additionally we performed a series of wash experiments to evaluate $\mathrm{CuO}$ migration from the micronanofibrous mats using UV-DRS. There was no change in the UV-DRS spectra of mats before and after incubation (Figure 7A). Also no significant change in the color of the mat was observed before and after incubation (Figure 7B). These findings clearly indicate that there is no, or negligible, $\mathrm{CuO}$ migration from the micronanofibrous mats. This is in accord with reports in the literature that copper is a long-lasting bactericide, and the release of copper is very slow and in very small quantities. ${ }^{26,27}$ Conclusively, our synthesized nanomatrix did not inhibit cell proliferation, 

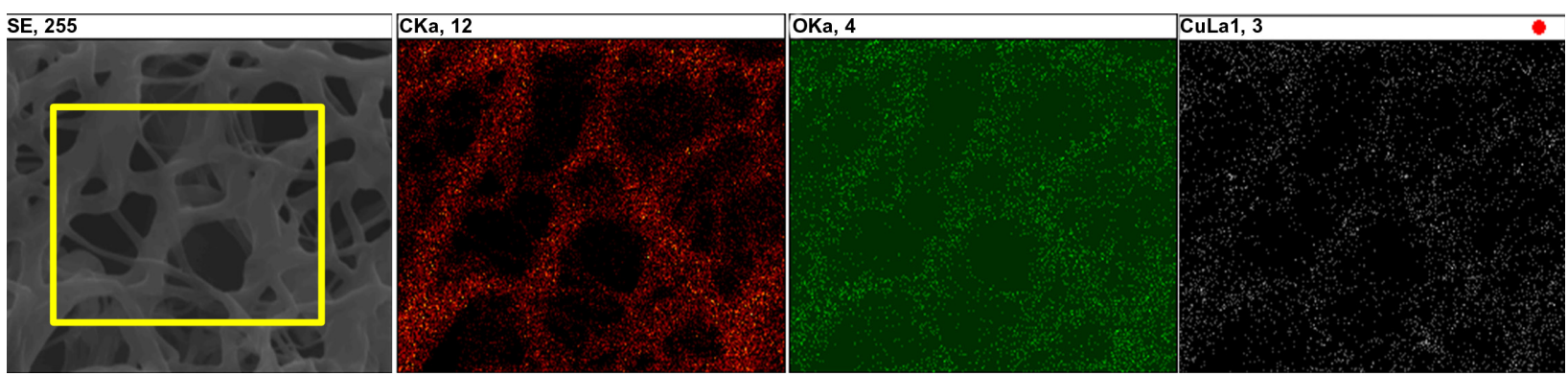

Figure 3 Electron probe microanalysis of hybrid micronanofibers.

and confluent cell growth was observed at the end of the culture period.

\section{Discussion}

Wound healing is an integrated biological process,$^{28}$ which takes place in various steps such as inflammation, wound contraction, the development of granulation tissue, remodeling of tissue, and scar formation. Normally, in the beginning of
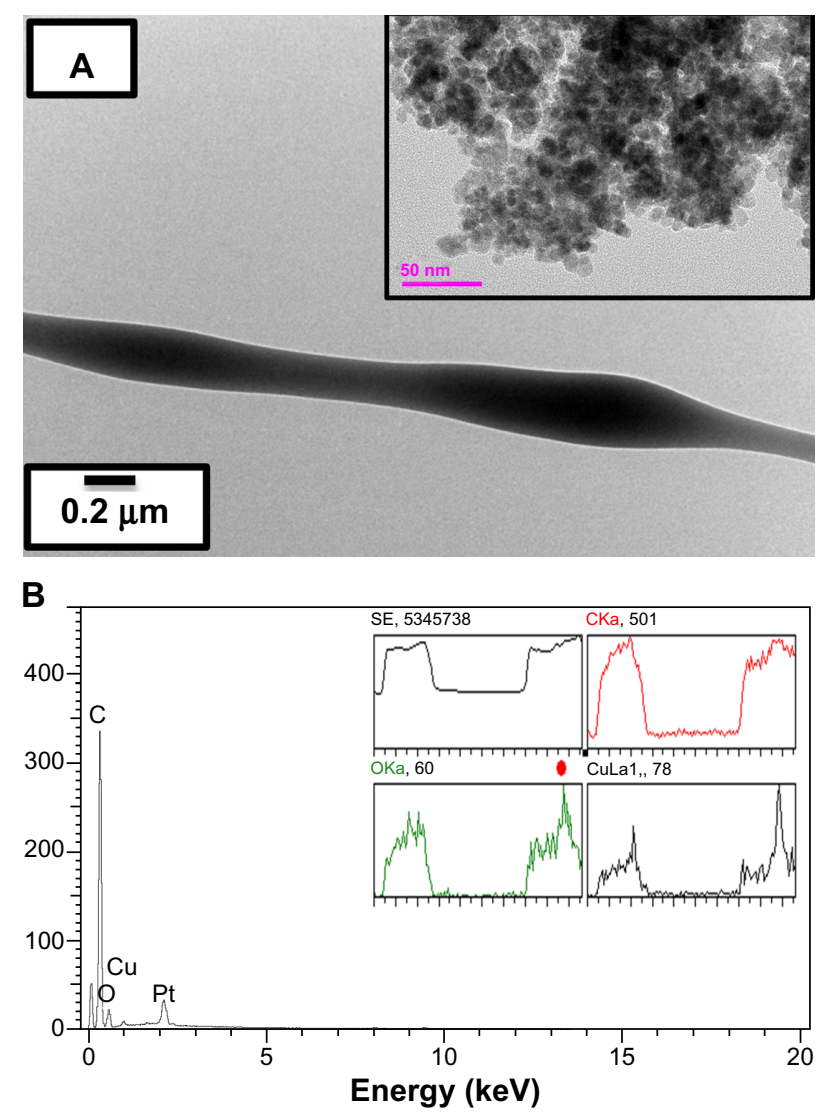

Figure 4 TEM analysis of micronanofiber and $\mathrm{CuO}$ nanocrystals (A), and EDX spectra analysis of hybrid micronanofiber and mat (B).

Notes: Representative TEM image of a single hybrid micronanofiber (A); inset shows the TEM image of $\mathrm{CuO}$ nanocrystals. EDX spectra of hybrid micronanofibers (B); inset shows the line mapping of the hybrid mat.

Abbreviations: $\mathrm{C}$, carbon; $\mathrm{Cu}$, copper; $\mathrm{CuO}$, copper oxide; $\mathrm{EDX}$, energy dispersive $\mathrm{X}$-ray; O, oxygen; TEM, transmission electron microscopy; Cka, peak of carbon; Oka, peak of oxygen; CuLal, peak of copper; Pt, platinum; SE, peak of selected area. the process, a fibrin clot forms the first line of defense against infections and is followed by a multiplication of healing cells, which gives rise to the granulation tissues. Lastly, remodeling of connective tissue and scarring ${ }^{29}$ occurs. Given this process, it is evident that a model wound dressing should be similar in morphology and function to ECM proteins, which control cellular activities such as cell differentiation. To attain these aforementioned objectives, the synthesized matrix must be compatible with human tissue. In this regard, wound dressing based on micronanofibers seems to be a promising material as compared to conventional materials because of intrinsic characteristics such as high surface area, high gas permeation, and conformability to outline the wounds. In addition to these properties, electrospun nanofibers can be fashioned into any size and dimension, depending upon the requirement. Thus our study was focused to fabricate novel micronanofibrous wound scaffold based on PU, virgin olive oil, and $\mathrm{CuO}$ nanocrystals. Olive oil has been touted as beneficial in historical scripts as long ago as 1,400 years and is imbued with diverse biologically active compounds which impart extraordinary health benefits. ${ }^{30}$ Additionally, it prevents the skin damage caused by UVA and $\mathrm{UVB}^{31}$ exposure, owing to the presence

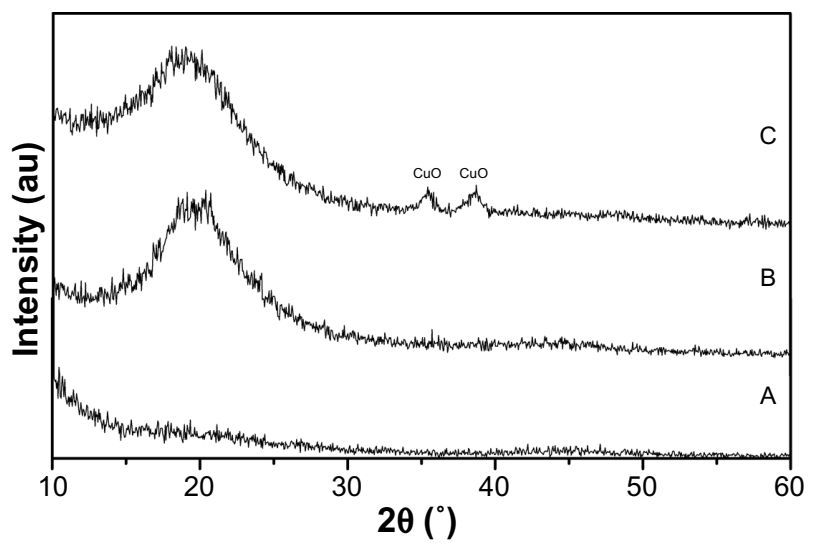

Figure 5 XRD pattern of pristine PU (A), olive oil/PU blend (B), and olive oil/ CuO-PU hybrid micronanofibers (C).

Abbreviations: $\mathrm{CuO}$, copper oxide; PU, polyurethane; XRD, X-ray diffraction. 

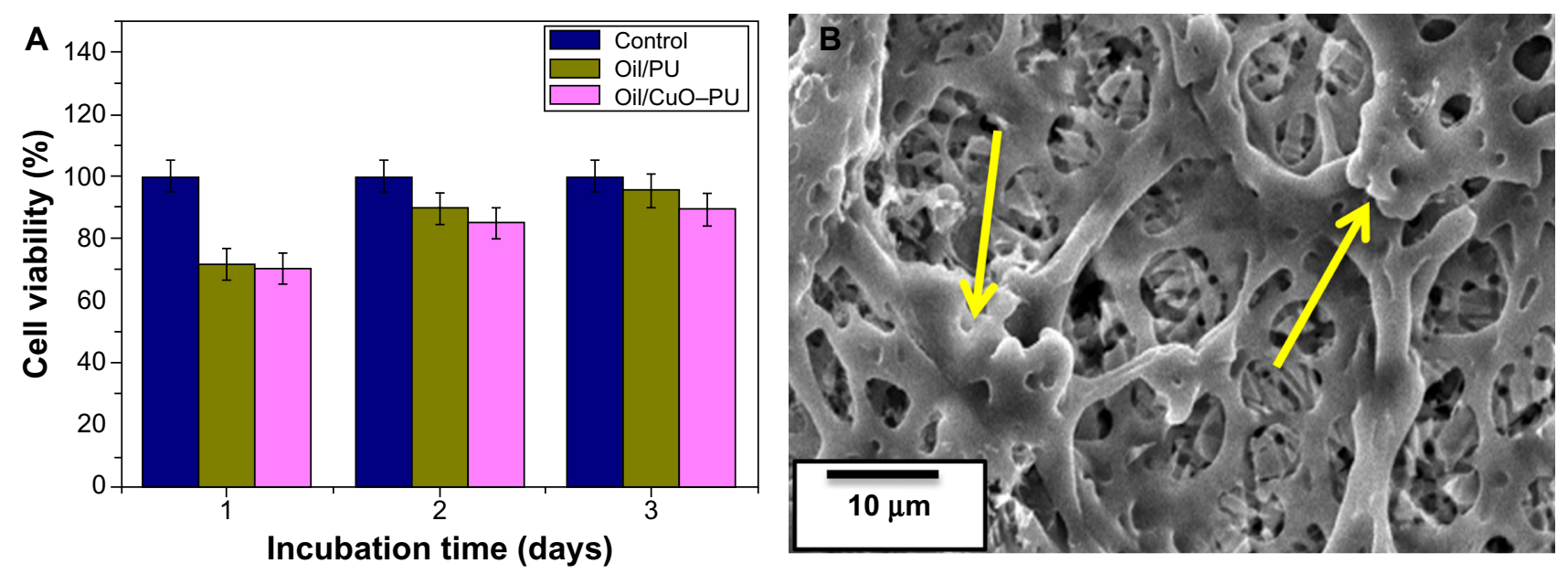

Figure 6 MTT assay results (A) and representative SEM image (B) of the cell fixation test on hybrid mat.

Notes: The viability of control cells were set $100 \%$, and viability relative to the control was expressed. The experiments were conducted at least in triplicate. Yellow arrows indicate the attachment of cells with hybrid micro/nanofibers.

Abbreviations: $\mathrm{CuO}$, copper oxide; MTT, 3-(4,5-dimethylthiazol-2-yl)-2,5-diphenyltetrazolium bromide; PU, polyurethane; SEM, scanning electron microscopy.
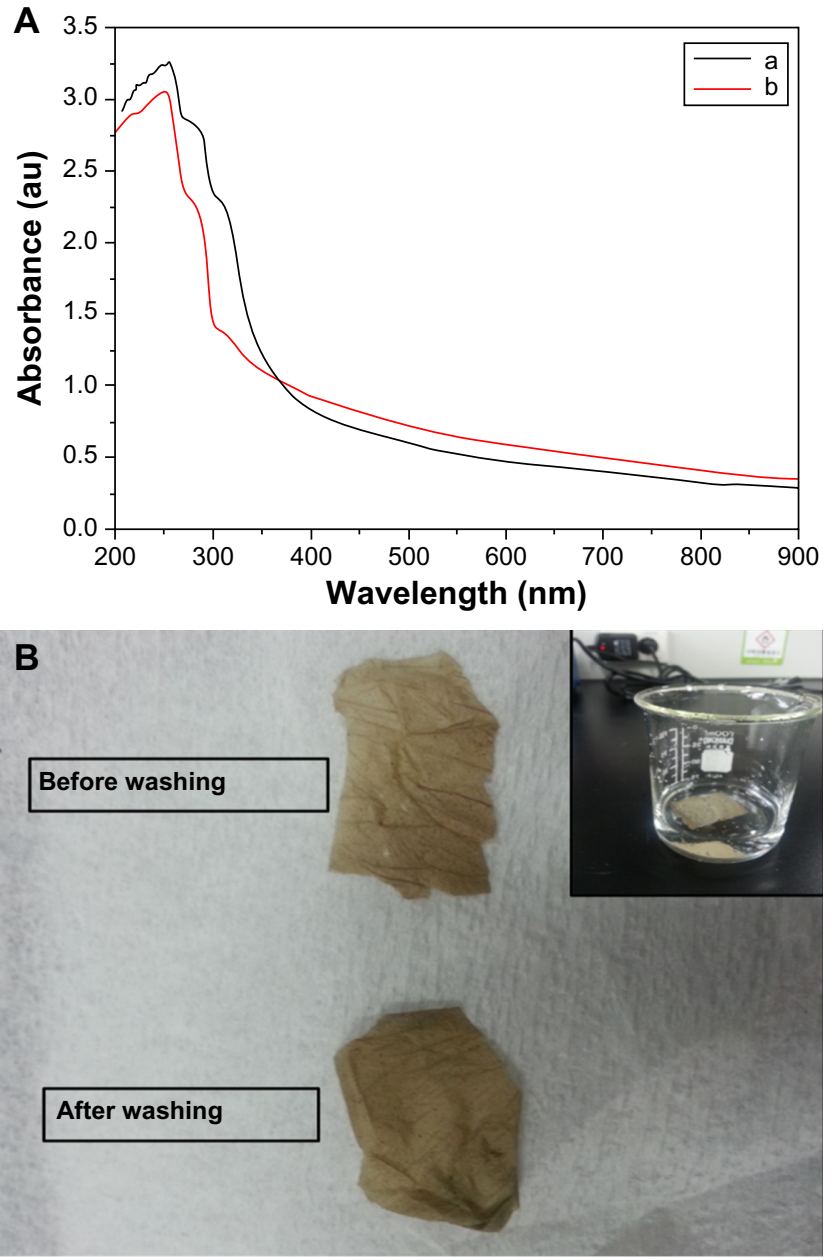

Figure 7 UV-DRS spectra of olive oil/CuO-PU hybrid mat before and after incubation in PBS (A), and a digital photograph of hybrid mat before and after incubation (B).

Note: The inset shows a picture of a hybrid mat in PBS for incubation (B).

Abbreviations: $\mathrm{CuO}$, copper oxide; PBS, phosphate buffered saline; PU, polyurethane; UV-DRS, ultraviolet-diffuse reflectance spectroscopic. of antioxidant substances. Besides safeguarding against sun induced skin cancer, virgin olive oil also has an effect on cytokine production when applied topically; that is why it is used in cosmetic and dermoprotective creams. The main constituents of olive oil are glycerol, pigments, aroma compounds, sterols, tocopherols, phenols, triacylglycerols, small quantities of free fatty acids, unidentified resinous components, and others. The unsaponifiable fraction, which covers a small percentage of approximately $0.5 \%-15 \%$, plays an important role in human health. The acidity of extra virgin olive oil can be no more than $1 \%$, and according to the International Olive Oil Council, the extra virgin olive oil must not contain more than $0.8 \%$ acidity. ${ }^{30}$ The beneficial effects of virgin olive oil may be due to components such as phenolic compounds, $\alpha$-tocopherol, carotenoids, and to the high unsaturated/saturated fatty acid ratio with oleic acid (monounsaturated fatty acid) as its main fatty acid. ${ }^{32,33}$ The polyphenols in Spain virgin olive oil have been described as the main components to which the anti-inflammatory properties are attributed after virgin olive oil consumption. Due to its medicinal benefits, olive oil is highly valued worldwide, particularly in the Middle East. Similarly, the curative ability ${ }^{34}$ and antibacterial properties ${ }^{24}$ of $\mathrm{CuO}$ are well recognized; therefore, it is predictable that a micronanofibrous scaffold containing $\mathrm{CuO}$ will have woundhealing effects with prominent antibacterial potential. Thus, a combination of olive oil, $\mathrm{CuO}$, and $\mathrm{PU}$ can be applied to recover damaged skin by improving cell viability and survival and thereby enhance wound healing. It is well established that electrospun nanofibers bear morphological and functional analogies with the fibrillar arrangement of living cells, and thus ought to be the best supporting material for living cells 
and tissues. ${ }^{35-37}$ Earlier workers have reported various biocompatible wound dressings; ${ }^{5,6,10-12}$ however, we herein report the synergistic effect of $\mathrm{CuO}$ and virgin olive oil for enhanced wound-healing application. The advantage of this proposed dressing is that it is based on a mixture of organic and inorganic components, supplemented by natural material. The synthesized micronanofibrous mat is cost-effective, and the fabrication method is simple. Overall, in the present study, the synthesized micronanofibers showed nontoxic behavior. Cells grown on the designed nanomatrix were very similar to the unexposed control cells in morphology and function. Moreover, the hybrid micronanofibers are bactericidal, therefore, on the basis of the results, it is supposed that the hybrid micronanofibers will support accelerated wound healing. In summary, our study clearly suggests a role for virgin olive oil and $\mathrm{CuO}$ in combination for wound management and demonstrates the usefulness of the electrospinning process for the fabrication of organic/inorganic composite wound dressing. The as-spun composite dressing possesses multifunctionality, such as obstructing access of infectious microbes to wounds, maintaining a hydrated environment, deodorizing the wounds, preventing apoptosis of wound repair cells, and so forth. Nevertheless, before these wound dressings can be applied to humans, the detailed curative effects on full thickness skin wounds will be investigated in in vivo models. A future study has been aimed in this regard and is in progress.

\section{Acknowledgments}

This work was fully supported by Research Funds of Chonbuk National University in 2013. This work has been partly supported by a grant from Next-Generation BioGreen 21 Program (No PJ008191) and FTA strategy issue (No PJ008525) Rural Development Administration, South Korea.

\section{Disclosure}

The authors report no conflicts of interest in this work.

\section{References}

1. Friess W. Collagen - biomaterial for drug delivery. Eur J Pharm Biopharm. 1998;45(2):113-136.

2. Jannesari M, Varshosaz J, Morshed M, Zamani M. Composite poly(vinyl alcohol)/poly(vinyl acetate) electrospun nanofibrous mats as a novel wound dressing matrix for controlled release of drugs. Int $J$ Nanomedicine. 2011;6:993-1003.

3. Kontogiannopoulos KN, Assimopoulou AN, Tsivintzelis I, Panayiotou C, Papageorgiou VP. Electrospun fiber mats containing shikonin and derivatives with potential biomedical applications. Int $J$ Pharm. 2011;409(1-2):216-228.

4. Wharram SE, Zhang X, Kaplan DL, McCarthy SP. Electrospun silk material systems for wound healing. Macromol Biosci. 2010;10(3): 246-257.
5. Khil MS, Cha DI, Kim HY, Kim IS, Bhattarai N. Electrospun nanofibrous polyurethane membrane as wound dressing. J Biomed Mater Res B Appl Biomater. 2003;67(2):675-679.

6. Rujitanaroj P, Pimpha N, Supaphol P. Wound-dressing materials with antibacterial activity from electrospun gelatin fiber mats containing silver nanoparticles. Polymer. 2008;49(21):4723-4732.

7. Albertini B, Di Sabatino M, Calonghi N, Rodriguez L, Passerini N. Novel multifunctional platforms for potential treatment of cutaneous wounds: development and in vitro characterization. Int J Pharm. 2013;440(2):238-249.

8. Ong SY, Wu J, Moochhala SM, Tan MH, Lu J. Development of a chitosan-based wound dressing with improved hemostatic and antimicrobial properties. Biomaterials. 2008;29(32):4323-4332.

9. Kim JO, Choi JY, Park JK, et al. Development of clindamycin-loaded wound dressing with polyvinyl alcohol and sodium alginate. Biol Pharm Bull. 2008;31(12):2277-2282.

10. Jayakumar R, Prabaharan M, Sudheesh Kumar PT, Nair SV, Tamura H. Biomaterials based on chitin and chitosan in wound dressing applications. Biotechnol Adv. 2011;29(3):322-337.

11. Zhou Y, Yang H, Liu X, Mao J, Gu S, Xu W. Electrospinning of carboxyethyl chitosan/poly(vinyl alcohol)/silk fibroin nanoparticles for wound dressings. Int J Biol Macromol. 2013;53:88-92.

12. Shalumon KT, Anulekha KH, Nair SV, Nair SV, Chennazhi KP, Jayakumar R. Sodium alginate/poly(vinyl alcohol)/nano $\mathrm{ZnO}$ composite nanofibers for antibacterial wound dressings. Int J Biol Macromol. 2011;49(3):247-254.

13. Assmann G, de Backer G, Bagnara S, et al. International consensus statement on olive oil and the Mediterranean diet: implications for health in Europe. The Olive Oil and the Mediterranean Diet Panel. Eur J Cancer Prev. 1997;6(5):418-421.

14. Owen RW, Giacosa A, Hull WE, et al. Olive-oil consumption and health: the possible role of antioxidants. Lancet Oncol. 2000;1:107-112.

15. Ozyilkan O, Colak D, Akcali Z, Basturk B. Olive: fruit of peace against cancer. Asian Pac J Cancer Prev. 2005;6(1):77-82.

16. Shah M, Adams-Huet B, Grundy SM, Garg A. Effect of a highcarbohydrate vs a high-cis-monounsaturated fat diet on lipid and lipoproteins in individuals with and without type 2 diabetes. Nutr Res. 2004;24(12):969-979.

17. Strychar I, Ishac A, Rivard M, et al. Impact of a high-monounsaturatedfat diet on lipid profile in subjects with type 1 diabetes. JAm Diet Assoc. 2003;103(4):467-474.

18. Visioli F, Galli C. The effect of minor constituents of olive oil on cardiovascular disease: new findings. Nutr Rev. 1998;56(5 Pt 1): $142-147$.

19. Kelly GS. Squalene and its potential clinical uses. Altern Med Rev. 1999;4(1):29-36.

20. Cornelli U. The antioxidant defence system in skin. Poster presented at: International Congress on Nutricosmeceutical, a Challenge for the Future; 6-8 Feb; 2002; Rome, Italy.

21. Ancora C, Roma C, Vettor M. Evaluation of cosmetic efficacy of oleoeuropein. Poster presented at: Symposium on the New Frontiers of Dermo-Cosmetology: Efficacy, Stability and Safety; November 4-6; 2004; Rome, Italy.

22. Sen CK, Khanna S, Venojarvi M, et al. Copper-induced vascular endothelial growth factor expression and wound healing. Am J Physiol Heart Circ Physiol. 2002;282(5):H1821-H1827.

23. Gorter RW, Butorac M, Cobian EP. Examination of the cutaneous absorption of copper after the use of copper-containing ointments. Am J Ther. 2004;11(6):453-458.

24. Hassan MS, Amna T, Yang OB, El-Newehy MH, Al-Deyab SS, Khil MS. Smart copper oxide nanocrystals: synthesis, characterization, electrochemical and potent antibacterial activity. Colloids Surf B Biointerfaces. 2012;97:201-206.

25. Hassan MS, Amna T, Sheikh FA, et al. Bimetallic Zn/Ag doped polyurethane spider net composite nanofibers: a novel multipurpose electrospun mat. Ceramics Int. 2013;39(3):2503-2510. 
26. Sheikh FA, Barakat NAM, Kanjwal MA, et al. Electrospun antimicrobial polyurethane nanofibers containing silver nanoparticles for biotechnological applications. Macromolecular Res. 2009;17(9):688-696.

27. Drelich J, Li B, Bowen P, Hwang JY, Mills O, Hoffman D. Vermiculite decorated with copper nanoparticles: novel antibacterial hybrid material. Appl Surf Sci. 2011;257(22):9435-9443.

28. Silva KA, Coelho MAZ, Calado VMA, Rocha-Leão MHM (2013) Olive oil and lemon salad dressing microencapsulated by freeze-drying. LWT-Food Sci Technol. 2013;50(2):569-574.

29. Morhenn VB. Keratinocyte proliferation in wound healing and skin diseases. Immunol Today. 1988;9(4):104-107.

30. Kiritsakis A, Markakis P. Olive oil: a review. Adv Food Res. 1987;31: 453-482.

31. Budiyanto A, Ahmed NU, Wu A, et al. Protective effect of topically applied olive oil against photocarcinogenesis following UVB exposure of mice. Carcinogenesis. 2000;21(11):2085-2090.

32. Cicerale S, Lucas LJ, Keast RS. Antimicrobial, antioxidant and antiinflammatory phenolic activities in extra virgin olive oil. Curr Opin Biotechnol. 2011;23(2):129-135.
33. Massaro M, De Caterina R. Vasculoprotective effects of oleic acid: epidemiological background and direct vascular antiatherogenic properties. Nutr Metab Cardiovasc Dis. 2002;12(1):42-51.

34. Tian X, Zhang Z, Wang S, Diao Y, Zhao Z, Lv D. Copper-taurine (CT): a potential organic compound to facilitate infected wound healing. Med Hypotheses. 2009;73(6):1048-1050.

35. Li WJ, Laurencin CT, Caterson EJ, Tuan RS, Ko FK. Electrospun nanofibrous structure: a novel scaffold for tissue engineering, J Biomed Mater Res. 2002;60(4):613-621.

36. Mo XM, Xu CY, Kotaki M, Ramakrishna S. Electrospun P(LLA-CL) nanofiber: a biomimetic extracellular matrix for smooth muscle cell and endothelial cell proliferation. Biomaterials. 2004;25(10):1883-1890.

37. Schindler M, Ahmed I, Kamal J, et al. A synthetic nanofibrillar matrix promotes in vivo-like organization and morphogenesis for cells in culture. Biomaterials. 2005;26(28):5624-5631.
International Journal of Nanomedicine

\section{Publish your work in this journal}

The International Journal of Nanomedicine is an international, peerreviewed journal focusing on the application of nanotechnology in diagnostics, therapeutics, and drug delivery systems throughout the biomedical field. This journal is indexed on PubMed Central, MedLine, CAS, SciSearch $\AA$, Current Contents ${ }^{\circledR} /$ Clinical Medicine,

\section{Dovepress}

Journal Citation Reports/Science Edition, EMBase, Scopus and the Elsevier Bibliographic databases. The manuscript management system is completely online and includes a very quick and fair peer-review system, which is all easy to use. Visit http://www.dovepress.com/ testimonials.php to read real quotes from published authors. 